\title{
Knowledge and Practice of Menstrual Hygiene Management Among High School Girls and the Impact on Education in the Sunyani West Municipal, Ghana
}

Kwame ADJEI-AMOAFO ( $\nabla$ amoafokwame2@gmail.com )

Kwame Nkrumah University of Science and Technology

\section{Research Article}

Keywords: Menstrual hygiene, sanitary material, menstruation

Posted Date: August 16th, 2021

DOI: https://doi.org/10.21203/rs.3.rs-813356/v1

License: (c) (i) This work is licensed under a Creative Commons Attribution 4.0 International License. Read Full License 


\section{Abstract}

\section{Introduction}

Most female adolescents in Ghana enter puberty unprepared and the information they receive is often selective and surrounded by many taboos and other restrictions. This study therefore seeks to assess the knowledge high school girls have concerning menstruation, how they practise menstrual hygiene and the impact menstrual hygiene management has on education.

\section{Methods}

A cross-sectional survey was carried out in conveniently selected JHS and SHS in the Sunyani West Municipality between March 19 and April 30,2018 using self-administered questionnaires to elicit information on demographic features, knowledge, practices and challenges of menstruation and its management. A chi-square analysis was used to determine the association between a number of outcomes and explanatory variables.

\section{Results}

A total of 306 students participated in the study with a response rate of $87.4 \%$. The mean age at menarche was $13.09 \pm 1.24$ years. From the study, $83.01 \%$ (254) were knowledgeable on MHM. Knowledge of MHM was significantly associated with ethnicity (p-value 0.028). Almost all the participants 95.10\% (291) used disposable sanitary material. From the study, $66.67 \%$ (204) had good practice of MHM. Practice of MHM was associated with religion ( $p$ value 0.037 ). The study revealed $27.45 \%$ (84) had ever absented themselves from school during menstrual period and majority of them $86.27 \%$ (264) were distracted about blood staining their dress during teaching.

\section{Conclusion}

The study group had high knowledge of MHM and a greater percentage observed good menstrual hygiene management. However, their knowledge of MHM does not necessarily translate into good practice of MHM.

\section{Introduction}

Menstrual Hygiene Management(MHM) is described as women and adolescent girls using a clean menstrual management material to absorb or collect blood that can be changed in privacy as often as necessary for the duration of the menstruation period, using soap and clean water for washing the body as required, and having access to facilities to dispose of used menstrual management materials(1). Research has shown that, in total, women spend six to seven years of their lives menstruating (2) and this is a worth-noting information for women and girls to have the necessary knowledge, facilities and cultural environment to manage menstruation hygienically. Although menstruation is a normal physiological process, it is associated with many misconceptions, beliefs and practices which may result in unfavourable health outcomes. Inability to properly manage menstrual hygiene during menstruation has resulted in serious health-related conditions including reproductive tract and urinary tract infections like chlamydia, gonorrhoea, chancroid and HIV/AIDS. Every year, it is estimated that one billion women globally are exposed to urogenital infections (3) and these may be as a result of poor menstrual hygiene management. Beginning of menstruation is considered a moment of joy in some geographical settings whiles at other places, onset of menstruation is tagged with restrictions, either dietary, social or any other form. During menstruation many girls experience varying forms of emotional disorders including fear, shame and guilt because of lack of cardinal information about menstruation. Handling menstruation is therefore considered a major challenge before every adolescent girl and has resulted in school-absenteeism and school dropouts among school going girls (4). Menstrual hygiene management is to ensure that women and girls can manage their periods in a way that is not only healthy, but also enable their full participation in school. If the issue of poor MHM is therefore well handled, it will go a long way to positively affect the educational outcome of most school girls.

There is a substantial gap in the knowledge about menstruation among adolescent girls globally. Many research studies have illustrated this gap and showed low levels of awareness and knowledge about menstrual hygiene among girls when they reach menarche. A study conducted by Stubbs in USA on the cultural perceptions and practices around menarche and adolescent menstruation revealed that most girls have poor knowledge about menstruation (5). In Africa, similar reports can be ascertained. In Nigeria, a cross-sectional study conducted in Sokoto, an urban town to assess the level of knowledge on menstruation and hygienic practices among adolescent school girls revealed that $65 \%$ of the study population had knowledge of menstrual hygiene (6). Most of the blame for low level may be attributed to social restrictions and the poor attitude of parents and teachers in educating adolescents plainly on related issues leading to inability of adolescent girls to access the right kind of information (7). Several other studies have been conducted over the years at different setting using different research methods to evaluate the awareness, knowledge and perceptions adolescent girls have towards Menstruation and its management. ChandraMouli and colleagues conducted a study to assess the knowledge and understanding of menarche and menstrual hygiene among adolescent girls of Low and Middle Income Countries (LMIC), like Ghana. They reported that menstruation is oftentimes associated with cultural norms, religious beliefs and taboos which affect the perception and responses of young girls towards its management. They also reported that many adolescent girls in LMIC are frequently ignorant and unprepared for menarche (Chandra-Mouli and Patel, 2017). A previous study conducted in India by (8) on perceptions regarding menstruation and Menstrual hygiene among adolescent girls, recounted in the study that majority of the students had heard of menstruation and more than half had acquired this knowledge before menarche. The study further revealed that about three-quarters (73.7\%) of the girls knew that menstruation was a normal occurrence while about $13.4 \%$ felt it was an abnormal occurrence.

MHM comprises the use of clean absorbable menstrual material, clean water and soap, privacy to change sanitary material as often as required, access to disposal facilities to dispose used sanitary materials (9). A primary key for women and girls is to have the requisite knowledge, appropriate facilities and the right cultural background to manage menstruation hygienically. Methods or practices of Menstrual Hygiene differ greatly across different settings but numerous research studies report extensive use of non-sanitary absorbents, inaccessibility to private facilities and clean water across Sub-Saharan Africa, 
Asia and the Middle East (10). Studies in Africa have found use of sanitary pads as low as $18 \%$ amongst Tanzanian school girls with the remainder using cloth or toilet paper (11). In Nigeria, a study conducted on Nigerian schoolgirls revealed $31-56 \%$ usage of toilet tissue or cloth to absorb the menstrual blood instead of menstrual pads $(12,13)$. A descriptive cross-sectional study carried out by Poureslami and Osati-Ashtiani reported that less than one-third $(32 \%)$ of the students practiced good MHM like bathing and using hygienic materials. The report further discovered that more than half of the responders took nonprescribed medicine for menstrual pain (14). cross-sectional study conducted in Ethiopia to assess the knowledge and practice of menstrual hygiene among high school girls revealed that less than half (39.9\%) of the respondents had good practice on menstrual hygiene. Majority of the girls (82.2 \%) were using absorbent material during menstruation. Half of girls (51.9\%) change their pads or clothes at least three times each day. $20.2 \%$ of the respondents were disposing their used sanitary pads in dustbin (15). The practice of MHM is also associated with restrictions mainly due to inadequate knowledge and wrong perception of MHM. For instance, a menstruating Muslim woman is not allowed to enter the mosque for prayer, touch the Qur'an, or fast in Ramadan because menstrual blood is considered unclean and impure (16) (17). A cross - sectional study conducted in Hyderabad, India to assess the knowledge, attitude and practices of Menstrual Hygiene among school-going adolescent girls revealed that about half (54.4\%) of the respondents were not allowed to visit holy places and $45 \%$ were restricted from performing any household activities.

MHM has received increasing attention as a public health issue mainly because of its impact on education of adolescent school girls (18), yet its implementation hasn't seen much of the light. According to UNESCO estimates, 130 million girls between the ages of 6 and 17 are out of school and 15 million girls of primary school age, half of which are in sub-Saharan Africa, will never go to school(19). Research studies have documented challenges girls face in managing their menses and the indicated health, education and psychosocial wellbeing consequences of poor management. A cross-sectional study conducted in Uganda in 2014 to examine menstrual hygiene practices and the extent to which poor MHM affects education, reported that more than half $(61.7 \%)$ of the responders missed school at least once every month due to menstruation. The study further revealed that the main reasons for absenteeism were due to lack of private changing or washing rooms at school (63.8\%), fear of blood staining clothes (59.4\%) and menstrual pains (51.4\%) (20). School attendance, lack of concentration and poor academic performance in class have been highlighted as significant consequences of poor MHM.(21). Because of this, girls usually lag in school lessons, especially in complicated and more detailed subjects where there is a gradual build up on previous knowledge. Negative psychosocial outcomes including shame, guilt, uncertainty, anxiety, lack of participation and fear of stigmatization have also been reported as important consequences of poor menstrual hygiene management (22-24).

The impact of MHM on adolescent school-girl cannot be underrated. Much attention is not given to the problem of MHM and studies conducted on MHM and its influence on girls' education are limited and scarce in Ghana. This study is therefore conducted with the aim of assessing the prevailing knowledge about menstruation and its hygienic management, identifying the practices of MHM and assessing the associated consequences of menstrual related problems on school attendance and dropout among adolescent school girls.

\section{Methods Study Area}

Sunyani West municipality is one of the twenty-seven (27) districts in the Brong Ahafo region. The municipality was established on 10 th March, 1989 by a legislative instrument (LI) in 1473. The Sunyani West Municipal covers a total land area of $506.7 \mathrm{~km}^{2}$. It is located at the heart of Brong Ahafo Region lying between Latitudes $7^{\circ} 20^{\prime} \mathrm{N}$ and $7^{\circ} 05^{\prime} \mathrm{N}$ and Longitudes $2^{\circ} 30^{\prime} \mathrm{W}$ and $2^{\circ} 10^{\prime} \mathrm{W}$. The population of Sunyani West Municipal, according to the 2010 Population and Housing Census is 123,224 representing $5.3 \%$ of the region's total population with majority of them being females (50.1\%). The municipality is predominantly urban with more than eight out of every 10 persons living in urban areas. There are 28,431 households in the district of which 84.6 percent are in urban localities. The municipal has a total dependency ratio of 54.0. The Sunyani West Municipality has diverse ethnic background which is predominantly inhabited by the Akan ethnic group. The municipality has a literate population of $81,118(85.9 \%)$ with a number of educational facilities from both the public and private sectors. Under the public sector, it has 111 basic schools, 50 junior high schools, five senior high/ vocational and two tertiary schools. The private sector on the other hand has 117 basic schools, 37 junior high school and four senior high/vocational schools. Six hospitals, twelve clinics, seven chips compound, three maternity homes and three (3) health centres provide health services to the district population of 123,224 according to the 2010 Population and Housing Census.

\section{Study design and Study period}

The study was descriptive and analytical in nature. It was conducted between 19th March and 20th April 2018. A school-based cross-sectional study design was employed with the use of a survey instrument (questionnaire) for data collection.

\section{Study population, Sampling size and Sampling methods}

The study population for the survey were female adolescents within the ages of 10 and 19 years who had attained menarche at the time of the study in selected Junior High Schools (Form one to Form three) and Senior High Schools (Form one to Form three) within the Sunyani West municipality. The study population also comprised students of different ethnic background including Ewe, Ga and Akan. Three hundred and six (306) adolescent girls were conveniently selected for the study. The sample size was determined by a single proportion (Cochrane) formula using,

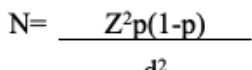

$\mathrm{d}^{2}$ 
The following assumptions were made;

\begin{tabular}{|l|}
\hline Where \\
\hline $\mathrm{N}=$ the required sample size \\
\hline $\mathrm{Z}=$ value at $95 \%$ Confidence Interval \\
\hline $\mathrm{p}=$ proportion of knowledge and practice of menstrual hygiene in Sunyani West Municipal \\
\hline$d=$ margin of error. \\
\hline
\end{tabular}

$Z=1.96, p=50 \%, d=0.05$

To compensate for the non-response rate, $10 \%$ of the determined sample was added up on the calculated sample size and the final sample size was found to be 422. Although the final sample size was 422, the number of respondents used for the study were 306 . This is because some of the students opted out in the course of the study and some also inadequately completed the questionnaire so those questionnaires were not used in the study analysis.

Four (4) Junior High Schools and two (2) Senior High Schools were conveniently selected for participation. These schools selected were Boahenkorkor Presby JHS, Saint Anselm's Anglican JHS, Regional Police JHS, Twene Amanfo SHS and Technical school and Sunyani Secondary School. The sampling technique used was convenient sampling. In the JHS, a female teacher was asked to group all the girls from JHS 1-3 who had attained menarche and 40-50 students were conveniently selected to partake in the study. In the SHS, girls from the Home Economics class were purposely selected because most of the students in the class were females. In schools where the Home Economics class were not up to the $40-50$ target that was set for each school, other girls from different classes were asked to participate in the study.

\section{Data collection techniques and Tools}

The preferred instrument adopted for data collection was a self -administered questionnaire. The questionnaire was made up of mostly closed ended questions with a few open-ended questions. The questionnaire was divided into four sections. Section A contained information on socio-demographic characteristics of the respondents. Section B was made up of questions that assessed the knowledge on Menstrual Hygiene Management of the study population. Section C included questions that assessed the Practice of Menstrual Hygiene Management of the study population. Section D was made up of questions to evaluate the Impact of MHM on Education. The questionnaire was developed based on previous studies (25-29) and adopted for this study setting.

Knowledge of MHM was assessed using four item questionnaire which included knowledge of menstruation before menarche, how menstruation is perceived, knowledge of last menstrual period and education received on MHM. Practice of MHM was also assessed using a seven-item questionnaire which includes; type of sanitary material used during menstruation, number of times sanitary material is changed, hand-washing before and after changing sanitary material, access to clean water and soap, privacy in school to change sanitary material, disposal of used sanitary material and restrictions encountered during menstruation. Impact of MHM on education was evaluated using five item questionnaire which included; absence from school during menstrual period, distraction in class during menstrual period, teasing by classmates, embarrassed when a male classmate realizes menstrual period and anger or moody during menstruation. Before the actual data collection, the questionnaire was pretested on 20 adolescent high school girls in a neighbouring town and the result was used to improve the phrasing of questions in the questionnaire.

\section{Data management and Analysis}

Data was coded and entered into SPSS Windows Version 25.0. The data was then exported to STATA Statistical Software Package, Version 14 for cleaning and analysis. Descriptive statistics comprising frequency, percentages, mean and standard deviations were used to give a clear picture of the sociodemographic variables like age, ethnicity, religion, educational level, guardian and the like. A bivariate analysis was performed between dependent variables (Knowledge and Practice of MHM) and each of the independent explanatory variables one at a time. The associations between the variables were measured and a p-value $<0.05$ was considered to be statistically significant in all cases.

The student's knowledge of menstruation and its hygiene management was scored using a scoring system adopted from previous study (30). Students' menstrual knowledge score was calculated out of the four knowledge specific questions. Each correct response earned one mark, whereas any wrong response attracted no mark and thus the sum score of knowledge was calculated ( 4 marks). The average score of menstrual knowledge (3.27 $\pm 0.80 S D)$ was used to decide the cutoffs of the rank. Respondents who scored 3-4 marks were categorized to have "Good knowledge of MHM" and those who scored 0-2 marks were categorized to have "Poor knowledge of MHM." Students' practice of menstrual hygiene score was also calculated out of the seven practice specific questions. Each correct response earned one mark, whereas any wrong response attracted no mark. The average score of menstrual hygiene practice (5.72 $\pm 1.10 S D)$ was used to group them. Respondents who scored 6-7 marks were categorized to have "Good practice of MHM" and those who scored 0-5 marks were categorized to have "Poor practice of MHM." Results from the study were presented in tables and charts.

\section{Ethical Consideration}

A departmental approval was first sought from Department of Community Health, KNUST SMS. Following the departmental approval, approval was also given by Ghana Education Service and Ghana Health Service, all at the municipal level. Permission was again granted by school heads and teachers of the selected schools in the municipality through a formal letter. The purpose of the study was explained to the students. The students were conveniently selected and asked to independently complete the questionnaire. Participants were told about their rights to withdraw from the study at any stage without any form of coercion as the study was voluntary. Confidentiality was assured by instructing the students not to write their names on the questionnaire paper. In each school, a female teacher was asked to oversee the conduct of the study because of how sensitive the study was and the fact that it was a male conducting 
the study. Where possible, all the boys in the class were asked to leave the class shortly before the study was conducted. There were no risks involved in the study, rather participants stood a chance of learning more about menstrual hygiene management.

\section{Results}

\section{Socio-demographic characteristics}

Table 1

shows the demographic characteristics of the study population. A total of 306 students participated in the study with a response rate of $87.4 \%$.

\begin{tabular}{|c|c|c|}
\hline Variable & Frequency(n) & Percentage (\%) \\
\hline \multicolumn{3}{|l|}{ Age } \\
\hline $11-13$ years & 51 & 16.67 \\
\hline $14-16$ years & 152 & 49.67 \\
\hline 17_and_above & 103 & 33.66 \\
\hline \multicolumn{3}{|l|}{ Ethnicity } \\
\hline Ewe & 20 & 6.54 \\
\hline $\mathrm{Ga}$ & 15 & 4.9 \\
\hline Akan & 215 & 70.26 \\
\hline Others & 56 & 18.3 \\
\hline \multicolumn{3}{|l|}{ Religion } \\
\hline Christian & 273 & 89.22 \\
\hline Muslim & 30 & 9.8 \\
\hline Traditionalist & 2 & 0.65 \\
\hline Others & 1 & 0.33 \\
\hline \multicolumn{3}{|c|}{ Educational level } \\
\hline JHS 1-3 & 199 & 65.03 \\
\hline SHS $1-3$ & 107 & 34.97 \\
\hline \multicolumn{3}{|l|}{ Guardian } \\
\hline Parent(s) & 268 & 87.58 \\
\hline Grandmother & 18 & 5.88 \\
\hline Sibling & 4 & 1.31 \\
\hline Others & 17 & 5.23 \\
\hline
\end{tabular}

Majority of the students (49.67\%) were between the ages of 14 and 16 years with the least been 11 and 13 years (16.67\%). Majority (70.26\%) of the students were Akan. Most of the participants were Christians (89.22\%). Majority of the respondents (65.03\%) were between JHS 1 to JHS 3 . Majority (87.58\%) of the participants were living with their parents at the time of the study. The mean age at menarche was $13.09 \pm 1.24$ SD years with an age range 10 and 16 years.

\section{Knowledge of menstrual hygiene management}

Regarding knowledge, majority 220 (71.90\%) of the respondents had some knowledge of menstruation before the onset of menarche. Mothers 113 (36.93\%) were the first source of information for majority of them, followed by school teachers, older sisters, friends and the least being grandmothers (Fig. 5 - 3 ). Bulk of the students $269(87.91 \%)$ perceived menstruation as a normal occurrence.

Almost all the participants 300 (98.04\%) had received some education on Menstrual Hygiene Management. Female school teachers 158 (51.63\%) were the leading source of education on MHM followed by mothers, older sisters and the least being friends and grandmothers (Fig. 5 - 4 ).

A good number of the respondents 179 (58.5\%) did not know their menstrual cycle length. Out of the total participants, 95 (31.05\%) did not know their Last menstrual period. Most of the students knew the duration of menstrual flow with just 14(4.58\%) of them who didn't know. Most of the participants 198 
(64.71\%) had lower abdominal pain as their menstrual problem.

Out of the study population with menstrual pain, $48.69 \%$ (149) of them had to rest to relieve menstrual pain followed by taking paracetamol, doing nothing, going to the hospital, taking herbal medicine and using warm compression (Table 5 - 2).

From the participants, 254 (83.01\%) of them scored greater than or equal to the mean and were considered knowledgeable (Table 5 - 3 ). A chi square test was performed to reveal statistically significant associations between knowledge of menstrual hygiene and the socio-demographic characteristics and other independent exploratory variables. The bivariate analysis (Table 5 - 4) revealed a statistically non-significant association between knowledge of menstrual hygiene and age ( $p$-value 0.205), religion ( $p$-value 1.000) and educational level ( $p$-value 0.527). Knowledge of Menstrual Hygiene Management was however significantly associated with ethnicity ( $p$-value 0.028$)$ and mother being the source of information for the adolescent girl before menarche ( $p$-value $<0.001)$.

Table 2: Respondents Knowledge about Menstrual Hygiene Management.

\begin{tabular}{|c|c|c|c|}
\hline Variables & Responses & Frequency (n) & Percentage (\%) \\
\hline \multirow[t]{2}{*}{ 1. How do you see menstruation? } & Normal & 269 & 87.91 \\
\hline & Illness & 37 & 12.09 \\
\hline \multirow[t]{2}{*}{ 2. Did you know menstruation before menarche? } & Yes & 220 & 71.9 \\
\hline & No & 86 & 28.1 \\
\hline 3. Do you remember your Last & Yes & 211 & 68.95 \\
\hline Menstrual Period? & No & 95 & 31.05 \\
\hline 4. Have you had any education on how to keep yourself clean during & Yes & 300 & 98.04 \\
\hline your menses? & No & 6 & 1.96 \\
\hline \multirow[t]{2}{*}{ Knowledge score (summary index) } & Knowledgeable & 254 & 83.01 \\
\hline & Not Knowledgeable & 52 & 16.99 \\
\hline
\end{tabular}


Table 3: Bivariate analysis of knowledge and other explanatory variables

\begin{tabular}{|c|c|c|c|}
\hline Variable & Knowledge grade & & P-value \\
\hline & Knowledgeable=52 (\%) & Not Knowledgeable=254 (\%) & \\
\hline Age & & & 0.205 \\
\hline $11-13$ years & $13(25)$ & $38(14.96)$ & \\
\hline $14-16$ years & $22(42.31)$ & 130(51.18) & \\
\hline 17 and above & 17(32.69) & 86(33.86) & \\
\hline Ethnicity & & & $0.028^{*}$ \\
\hline Ewe & $4(7.69)$ & $16(6.30)$ & \\
\hline $\mathrm{Ga}$ & $7(13.46)$ & $8(3.15)$ & \\
\hline Akan & $32(61.54)$ & 183(72.05) & \\
\hline Others & $9(17.31)$ & $47(18.50)$ & \\
\hline Religion & & & 1.00 \\
\hline Christian & 47(90.38) & 226(88.98) & \\
\hline Muslim & $5(9.62)$ & $25(9.84)$ & \\
\hline Traditional & $0(0)$ & $2(0.79)$ & \\
\hline Others & $0(0)$ & $1(0.39)$ & \\
\hline Educ. Level & & & 0.527 \\
\hline JHS 1-3 & $36(69.23)$ & $163(64.17)$ & \\
\hline SHS 1-3 & $16(30.77)$ & $91(35.83)$ & \\
\hline \multicolumn{4}{|c|}{ Mother as source } \\
\hline of information & & & $<0.001^{*}$ \\
\hline Yes & $5(9.62)$ & $108(42.52)$ & \\
\hline No & 47(90.38) & $146(57.48)$ & \\
\hline Restrictions & & & 0.218 \\
\hline Yes & $26(50)$ & $152(59.84)$ & \\
\hline No & $26(50)$ & 102(40.16) & \\
\hline
\end{tabular}

*statistically significant, p-value<0.05

\section{PRACTICE OF MENSTRUAL HYGIENE}

During menstrual period, majority of the study participants 291 (95.10\%) used disposable sanitary pad, followed by piece of cloth 7 (2.29\%), cotton wool 5 (1.63\%) with the least being toilet paper $3(0.98 \%)$. 
Table 4: Respondents Menstrual Hygiene Practice during menstruation. N=306

\begin{tabular}{|c|c|c|}
\hline Variables & Responses & Frequency (\%) \\
\hline \multirow[t]{2}{*}{ 1. What type of sanitary material do you use? } & Disposable Sanitary pad & 291(95.1) \\
\hline & *Others & $15(4.9)$ \\
\hline 2. How many times do you change your & Once & $5(1.63)$ \\
\hline sanitary material in a day during menstruation? & Two or more & $301(98.37)$ \\
\hline 3. Do you wash your hands before and after & Yes & $244(79.74)$ \\
\hline using the sanitary material? & No & $62(20.26)$ \\
\hline 4. Do you have access to clean water and & Yes & 269(87.91) \\
\hline soap for washing during menses? & No & $37(12.09)$ \\
\hline 5. Do you have a place in school to change & Yes & $226(73.86)$ \\
\hline sanitary material? & No & $80(26.14)$ \\
\hline 6. How do you dispose of used sanitary & Closed bin/Refuse damp & $242(79.08)$ \\
\hline material? & Pit latrine/Water closet & $64(20.92)$ \\
\hline 7. Are you restricted in any activity during & Yes & $178(58.17)$ \\
\hline Menstruation? & No & $128(41.83)$ \\
\hline \multirow[t]{2}{*}{ Practice Score (summary index) } & Poor Practice & 102(33.33) \\
\hline & Good Practice & $204(66.67)$ \\
\hline
\end{tabular}

*Others; piece of cloth, toilet paper, cotton wool

The queries on the frequency of change of sanitary material in a day during menstruation revealed that $182(59.48 \%)$ changed sanitary material twice a day, $108(35.29 \%)$ changed three times a day, 11 (3.59\%) four times or more and 5 (1.63\%) once a day. More than half (79.74\%) of the respondents wash their hands before and after changing sanitary material. 
Table 5: Predictors of practice of menstrual hygiene (bivariate analysis)

\begin{tabular}{|c|c|c|c|}
\hline \multirow[t]{2}{*}{ Variable, $n=306$} & \multicolumn{2}{|l|}{ Practice of menstrual hygiene } & \multirow[t]{2}{*}{ P-value } \\
\hline & Poor=102 (\%) & Good=204 (\%) & \\
\hline Age & & & 0.119 \\
\hline $11-13$ years & 12(11.76) & $39(19.12)$ & \\
\hline $14-16$ years & $49(48.04)$ & 103(50.49) & \\
\hline 17 and above & $41(40.20)$ & $62(30.39)$ & \\
\hline Ethnicity & & & 0.633 \\
\hline Ewe & $6(5.88)$ & $14(6.86)$ & \\
\hline $\mathrm{Ga}$ & $6(5.88)$ & $9(4.41)$ & \\
\hline Akan & 75(73.53) & $140(68.63)$ & \\
\hline Others & $15(14.71)$ & $41(20.10)$ & \\
\hline Educational level & & & 0.309 \\
\hline JHS 1-3 & $62(60.78)$ & 137(67.16) & \\
\hline SHS 1-3 & $40(39.22)$ & $67(32.84)$ & \\
\hline \multicolumn{4}{|c|}{ How to wipe genitals } \\
\hline \multicolumn{2}{|c|}{ after urination/defecation } & & $0.001^{*}$ \\
\hline From back to front & $14(13.73)$ & $63(30.88)$ & \\
\hline From front to back & $87(85.29)$ & $141(69.12)$ & \\
\hline Don't wipe & $1(0.98)$ & $0(0)$ & \\
\hline \multicolumn{4}{|l|}{ Embarrassed when } \\
\hline \multicolumn{4}{|c|}{ male classmate learns } \\
\hline \multicolumn{2}{|c|}{ you are in your menses } & & $0.01 *$ \\
\hline Yes & $30(29.41)$ & $33(16.18)$ & \\
\hline No & 72(70.59) & 171(83.82) & \\
\hline & *statistically significant, p-valu & & \\
\hline
\end{tabular}


Table 5-7: Cont'd, predictors of practice of menstrual hygiene (bivariate analysis)

\begin{tabular}{|c|c|c|c|}
\hline Variable, $n=306$ & Practice of menstrual hygiene & & P-value \\
\hline & Poor $=102(\%)$ & Good $=204(\%)$ & \\
\hline Religion & & & $0.008^{*}$ \\
\hline Christian & $94(92.16)$ & 179(87.75) & \\
\hline Muslim & $5(4.90)$ & $25(12.25)$ & \\
\hline Traditional & $2(1.96)$ & $0(0)$ & \\
\hline Others & $1(0.98)$ & $0(0)$ & \\
\hline \multicolumn{4}{|l|}{ Headache as a } \\
\hline Menstrual problem & & & $0.0026^{\star}$ \\
\hline Yes & 14(13.73) & $51(25)$ & \\
\hline No & $88(86.27)$ & $153(75)$ & \\
\hline \multicolumn{4}{|l|}{ Report to hospital } \\
\hline for menstrual relief & & & $0.037 *$ \\
\hline Yes & $3(2.94)$ & $20(9.80)$ & \\
\hline No & 99(97.06) & $184(90.20)$ & \\
\hline
\end{tabular}

*Statistically significant, p-value $<0.05$

Majority 269 (87.91\%) have access to clean water and soap for washing hands during menstruation. Two hundred and twenty-six (73.86\%) of the students had places in school where they could change sanitary material. One hundred and thirty $(42.48 \%)$ reported that they disposed sanitary material into closed bins followed by refuse damp 112 (36.60\%), pit latrine 46 (15.03\%) and water closet 17 (5.56\%). One person burns sanitary material after usage as a way of disposal. The result of the study reveals that, out of the 178 responders who are restricted during menstruation, $37.58 \%$ are restricted from certain foods, followed by sports, religious function and cooking (Figure 5-5).

The students' practice of Menstrual Hygiene was scored using a scoring system. The menstrual hygiene practice score was calculated out of seven (7) practice specific questions. Each correct response earned one mark whereas any wrong any wrong response attracted no mark and thus the sum score of practice was generated (7 marks). The mean score of Menstrual Hygiene (5.72 +/- 1.10) was used to decide cut-offs of the rank. Respondents that scored $0-5$ marks were considered practising poor menstrual hygiene; whereas those that scored 6-7 marks were reasoned to practise good menstrual hygiene. A bivariate analysis revealed a statistically non- significant association between practice of menstrual hygiene and age ( $p$-value 0.119$)$, ethnicity ( $p$-value 0.633$)$ and educational level ( $p$-value 0.309). However, menstrual hygiene Practice was significantly associated with religion ( $p$-value 0.008$)$, headache as a menstrual problem ( $p$-value 0.026 ), report to hospital for menstrual pain relief ( $p$-value 0.037 ), how to wipe genital after urination ( $p$-value 0.001$)$ and feeling embarrassed when a male classmate realizes menstrual period ( $p$-value 0.01$)$

Impact of menstrual hygiene management on education

From the survey, eighty-four (27.45\%) of the study population had ever absented themselves from school during the menstrual period. Of those who had ever absented themselves, majority of them 67 (79.76) were absent because of menstrual pain and discomfort followed by being scared that the dress will be soiled by blood in school 34 (40.47\%), shy of people knowing of their menstrual period $19(22.62 \%)$, lack of privacy in school 17 (20.24\%) with the least reason $11(13.1 \%)$ being because there is no water and soap in school for washing after changing sanitary material.

Two hundred and sixty-four (86.27\%) of the students were worried or distracted about blood staining dress when teaching is ongoing. Fifty-six (18.30\%) were teased or embarrassed by classmates during menstrual period. More than half of the study population felt shy $189(61.76 \%)$ when the male classmates realizes they are in their menstrual period. One hundred and sixty-five (53.92\%) were mostly moody during the menstrual period. 
Table: Percentage distribution of the impact of Menstrual Hygiene Management

\begin{tabular}{llll} 
Variable & Response & Frequency & Percentage \\
\hline 1.Absenteeism during & Yes & 84 & 27.45 \\
\hline menstruation & No & 222 & 72.55 \\
\hline 2.Distracted about blood stain & Yes & 264 & 86.27 \\
\hline during teaching & No & 42 & 13.73 \\
\hline 3.Teased by classmates during & Yes & 56 & 18.3 \\
\hline menstruation & No & 250 & 81.7 \\
\hline 4.Embarrassed when male & Yes & 63 & 20.59 \\
\hline realizes menstrual period & No & 243 & 79.41 \\
\hline 5.Moody during Menstruation & Yes & 165 & 53.92 \\
\hline & No & 141 & 46.08
\end{tabular}

\section{Discussion}

This study applied a cross-sectional design to assess the knowledge, practice and impact of menstrual hygiene management among adolescent high school girls in selected JHS and SHS in the Sunyani West District. The average age at menarche from this study was $13.09 \pm 1.24$ years which is lower than mean ages reported by Adadevoh et al and other studies $(31,32)$.

In this study, more than half (83.01\%) of the students had good knowledge about menstruation and menstrual hygiene. Several studies reported low to average levels of awareness of menstruation at menarche between $36.9 \%$ and $67.5 \%(14,29,33)$. This study however recorded $71.90 \%$ of the respondents stating that they knew what menstruation was before menarche. Mothers were stated by majority $(36.93 \%)$ of respondents to be their foremost source of information about menstruation before menarche as reported by many studies $(1,33)$. From previous studies, more than half of girls see menstruation as a normal physiological occurrence and this was consistent with this study where most of the girls (87.91\%) perceived menstruation as a normal occurrence and not an illness. Almost all the girls (98.04\%) had received education about Menstrual Hygiene Management and most of the education was received from school teachers $(51.63 \%)$ and mothers $(50.33 \%)$. One possible reason for teachers being the major source of information on menstruation in this study is because, in Ghana students are taught reproductive organs and their functions in Integrated Science lessons right from primary five and the teachers may have introduced menstruation when teaching organs of the reproductive system. Most of the participants (64.71\%) in this study had lower abdominal pain as their major menstrual problem as has been reported in other research studies (Adinma and Adinma, 2008; Sommer et al., 2014; Das et al., 2015). From the bivariate analysis, there was a statistically significant association between knowledge of menstrual hygiene and ethnicity ( $p$ value 0.028 ). This could be explained that some tribes and ethnic groups have some belief systems and taboos that restrict women during their menstrual period and this is likely to affect their knowledge level. As would have been expected, a student in SHS who is older will be knowledgeable than a JHS student who is younger. It was however surprising to notice from this study that knowledge of menstrual hygiene was not significantly associated with both age ( $p$ value 0.205$)$ and educational level ( $p$ value 0.527).

In this study, 66.67\% (204) of the responders had good practice of menstrual hygiene. The finding of this study was lower than studies conducted in Ethiopia and North western Nigeria which were $90.9 \%$ and $88.7 \%$, respectively $(35,36)$. From this study, almost all the respondents used disposable sanitary material (95.10\%). This finding however contradicts reports from other research studies where less than half of the participants used disposable sanitary pads (Thakur et al., 2014; Chandra-Mouli and Patel, 2017). Almost everyone used a disposable sanitary material probably because Sunyani West municipal is mostly urban dominated and the sanitary materials may be readily available and affordable. Only $2.29 \%$ used piece of cloth and these findings were high in other studies (Sumpter and Torondel, 2013; Das et al., 2015; Of, 2015a). Previous research reveals that more than $90 \%$ of school girls changed their sanitary material two or more times a day $(13,42)$ and this was consistent with this study where almost all the students in the study population $(98.37 \%)$ changed their sanitary material at least twice a day. Washing of hands before and after changing sanitary material prevent contamination of hands with menstrual products that can cause infections $(27,43)$. From the study, majority of the adolescent girls $(79.74 \%)$ wash the hands before and after changing the sanitary material but this finding was not consistent with other study findings $(27,44)$. According to this study $87.91 \%$ had access to clean water and soap during menstrual period and this may be reason most of them washed their hands before and after changing sanitary pads. Many researches reveal that most schools do not have a private facility in school to change sanitary material during menstruation and these have contributed to the wrong practice of MHM (Girls and Challenges, 2016; Kuhlmann, Henry and Wall, 2017). More than half (58.17\%) of the respondents practised various restrictions during menstruation. This finding was however high (70\%-90\%) in several studies conducted in India (Jain et al., 2017; M. U. Alam et al., 2017). The chi square analysis showed a statistically significant association between practice of menstrual hygiene and religion ( $p$ value 0.008). This may be explained that religion affects the belief systems and perception about menstruation and this may affect practice of MHM. There was a significant association between practice of MHM and how to wipe genital during urination ( $p$ value 0.001 ). This finding may also be due to the fact that wiping from back to front may introduce faecal matter containing microbes into the genital region leading to reproductive tract infections.

From the survey, less than half $(27.45 \%)$ of the participants had ever absented themselves from school during menstrual period. These results were high in other study areas; in Uganda (61.7\%) and Ethiopia (51.2\%) $(20,42)$ Another study conducted in Ethiopia however revealed a lower finding (17\%) (30). From the study, of those who absented themselves from school, the majority of them were absent because of menstrual pain and discomfort (79.76\%) followed by 
being scared that dress will be soiled by blood in school (40.47\%). This finding was consistent with other research findings which reports that over $67 \%$ absented school due to menstrual pain $(10,14)$. Menstruation from research findings has revealed its effect on psychological well-being of the adolescent girl (18). At the time of the study, it was alarming to record that majority $(86.27 \%)$ of the students were distracted and worried about blood staining dress while teaching was ongoing. It was alarming because almost all the students in this study used disposable sanitary material which has been established to be the most hygienic and safest material for absorbing menstrual blood without leakage (Sumpter and Torondel, 2013). These findings coincided with other studies which revealed that more than half of students were distracted and lost concentration in class during menstrual period (Article, 2012; Girls and Challenges, 2016; Chandra-Mouli and Patel, 2017). Very few respondents (18.30\%) were teased or embarrassed by classmates during menstrual period. This figure was however relatively higher compared to findings from other studies $(24,30,37)$. With reference to a study conducted in Kenya, some girls describe emotional effects of menstruation including boredom, being moody, feeling lonely or shy and not wanting to talk to others (24). At the time of the study, more than half of the students who participated in the study were mostly moody during the menstrual period.

\section{Declarations}

Competing interests: The author declares no competing interests

\section{References}

1. Das P, Baker KK, Dutta A, Swain T, Sahoo S, Das BS, et al. Menstrual Hygiene Practices, WASH Access and the Risk of Urogenital Infection in Women from Odisha, India. Wilson BA, editor. PLoS One [Internet]. 2015 Jun 30 [cited 2018 Sep 12];10(6):e0130777. Available from: http://dx.plos.org/10.1371/journal.pone.0130777

2. Mahon T, Fernandes M. Menstrual hygiene in South Asia: A neglected issue for WASH (water, sanitation and hygiene) programmes. Gend Dev. 2010;18(1):99-113.

3. Reid G, Bruce AW. Urogenital infections in women: can probiotics help ? 2003;428-32.

4. Alam M-U, Luby SP, Halder AK, Islam K, Opel A, Shoab AK, et al. Menstrual hygiene management among Bangladeshi adolescent schoolgirls and risk factors affecting school absence: results from a cross-sectional survey. BMJ Open [Internet]. 2017 Jul 9 [cited 2018 Sep 6];7(7):e015508. Available from: http://bmjopen.bmj.com/lookup/doi/10.1136/bmjopen-2016-015508

5. Stubbs ML. Cultural Perceptions and Practices around Menarche and Adolescent Menstruation in the United States. Ann N Y Acad Sci [Internet]. 2008 Jun 1 [cited 2018 Oct 28];1135(1):58-66. Available from: http://doi.wiley.com/10.1196/annals.1429.008

6. Oche M, Umar a, Gana G, Ango J. Menstrual health: the unmet needs of adolescent girls' in Sokoto, Nigeria. Sci Res Essays [Internet]. 2012;7(3):410-8. Available from:

http://www.researchgate.net/profile/Oche_M_Oche/publication/259571441_Menstrual_health_the_unmet_needs_of_adolescent_girls'in_Sokoto_Nigeria/I

7. Mudey AB, Kesharwani N, Mudey GA, Goyal RC. A Cross-sectional Study on Awareness Regarding Safe and Hygienic Practices amongst School Going Adolescent Girls in Rural Area of Wardha District, India. Glob J Health Sci [Internet]. 2010;2(2):225. Available from:

http://www.ccsenet.org/journal/index.php/gjhs/article/view/5437

8. Shanbhag D, Shilpa R, D'Souza N, Josephine P, Singh J, Goud BR. Perceptions regarding menstruation and practices during menstrual cycles among high school going adolescent girls in resource limited settings around Bangalore city, Karnataka, India. Int J Collab Res Intern Med Public Heal [Internet]. 2012;4(7):1353-62. Available from: http://www.scopus.com/inward/record.url?eid=2-s2.0-84863848244\&partnerlD=tZOtx3y1

9. Sommer M, Vasquez E, Worthington N, Sahin M, Dooley T. WASH in Schools Empowers Girls' Education. WASH Sch Empower Girls' Educ Proc Menstrual Hyg Manag Sch Virtual Conf 2013 [Internet]. 2014;56. Available from: http://wsscc.org/resources-feed/menstrual-hygiene-in-schools-empowers-girlseducation-conference-proceedings-2013/\%5Cnhttp://wsscc.org/wpcontent/uploads/2016/06/WASH_in_Schools_Empowers_Girls_Education_Proceedings_of_Virtual_MHM_virtual_conference_2013.p

10. Sumpter C, Torondel B. A Systematic Review of the Health and Social Effects of Menstrual Hygiene Management. PLoS One. 2013;8(4).

11. Baisley K, Changalucha J, Weiss HA, Mugeye K, Everett D, Hambleton I, et al. Bacterial vaginosis in female facility workers in north-western Tanzania: Prevalence and risk factors. Sex Transm Infect. 2009;85(5):370-5.

12. Adinma ED, Adinma JI. Perceptions and Practices on Menstruation. Afr J Reprod Health. 2008;12(1):74-83.

13. I.Zafar. Research Article. Psychol Sci. 1998;9(3):176-82.

14. Poureslami M, Osati-Ashtiani F. Assessing knowledge, attitudes, and behavior of adolescent girls in suburban districts of Tehran about dysmenorrhea and menstrual hygiene. J Int Womens Stud [Internet]. 2002;3(2):1-11. Available from: http://www.scopus.com/inward/record.url?eid=2-s2.018544372589\&partnerID=40\&md5=4f08536e8cabf32b22240933a03a954e

15. Upashe SP, Tekelab T, Mekonnen J. Assessment of knowledge and practice of menstrual hygiene among high school girls in Western Ethiopia. BMC Womens Health [Internet]. 2015;15(1):84. Available from: http://bmcwomenshealth.biomedcentral.com/articles/10.1186/s12905-015-0245-7

16. Tork HMM, Al Hosis KF. Effects of reproductive health education on knowledge and attitudes among female adolescents in Saudi Arabia. J Nurs Res. 2015;23(3):236-42.

17. Gopalakrishnan. Breaking the silence: Menstruation myths busted I Sanitation - India Water Portal [Internet]. 2015 [cited 2018 Sep 14]. Available from: http://sanitation.indiawaterportal.org/english/node/3489

18. Hennegan J, Dolan C, Wu M, Scott L, Montgomery P. Measuring the prevalence and impact of poor menstrual hygiene management: a quantitative survey of schoolgirls in rural Uganda. BMJ Open [Internet]. 2016 Dec 30 [cited 2018 Sep 6];6(12):e012596. Available from:

http://bmjopen.bmj.com/lookup/doi/10.1136/bmjopen-2016-012596

Page $12 / 15$ 
19. UNFPA, UNESCO, WHO. Sexual and reproductive Health of Young People in Asia and the Pasific. 2015;

20. Boosey R, Prestwich G, Deave T. Menstrual hygiene management amongst schoolgirls in the Rukungiri district of Uganda and the impact on their education: A cross-sectional study. Pan Afr Med J. 2014;19:1-13.

21. Grant M, Lloyd C, Mensch B. Menstruation and School Absenteeism: Evidence from Rural Malawi. Comp Educ Rev [Internet]. 2013 May 1 [cited 2018 Sep 13];57(2):260-84. Available from: http://www.ncbi.nlm.nih.gov/pubmed/25580018

22. Hennegan J, Dolan C, Wu M, Scott L, Montgomery P. Measuring the prevalence and impact of poor menstrual hygiene management: A quantitative survey of schoolgirls in rural Uganda. BMJ Open. 2016;6(12).

23. Rashid SF. Providing sex education to adolescents in rural Bangladesh: Experiences from BRAC. Gend Dev [Internet]. 2000 Jul [cited 2018 Sep 13];8(2):28-37. Available from: http://www.ncbi.nlm.nih.gov/pubmed/12296150

24. Mason L, Nyothach E, Alexander K, Odhiambo FO, Eleveld A, Vulule J, et al. 'We Keep It Secret So No One Should Know' - A Qualitative Study to Explore Young Schoolgirls Attitudes and Experiences with Menstruation in Rural Western Kenya. Molyneux C “Sassy," editor. PLoS One [Internet]. 2013 Nov 14 [cited 2018 Sep 13];8(11):e79132. Available from: http://dx.plos.org/10.1371/journal.pone.0079132

25. Crofts T, Fisher J. Menstrual hygiene in Ugandan schools: an investigation of low-cost sanitary pads. J Water, Sanit Hyg Dev [Internet]. $2012 ; 2(1): 50$. Available from: http://washdev.iwaponline.com/cgi/doi/10.2166/washdev.2012.067

26. Zegeye DT, Megabiaw B, Mulu A. Age at menarche and the menstrual pattern of secondary school adolescents in northwest Ethiopia. BMC Womens Health. 2009;9:29.

27. Water-Aid. Is menstrual hygiene and management an issue for adolescent school girls- A comparative study of four schools in different settings of Nepal. 2009;1-32.

28. Singh A. Place of menstruation in the reproductive lives of women of rural North India. Indian J Community Med [Internet]. 2006 [cited 2018 Sep 13];31(1):10. Available from: http://www.ijcm.org.in/text.asp?2006/31/1/10/54923

29. Dasgupta A, Sarkar M. Menstrual Hygiene: How Hygienic is the Adolescent Girl? Indian J Community Med [Internet]. 2008 Apr [cited 2018 Sep 13];33(2):77-80. Available from: http://www.ncbi.nlm.nih.gov/pubmed/19967028

30. Tegegne T, Sisay M, Keerti J, Pravin Y, Adhikari P, Kadel B, et al. Menstrual hygiene management and school absenteeism among female adolescent students in Northeast Ethiopia. BMC Public Health [Internet]. 2014;14(1):1118. Available from:

http://bmcpublichealth.biomedcentral.com/articles/10.1186/1471-2458-14-1118

31. Adadevoh SWK, Agble TK, Hobbs C, Elkins TE. Menarcheal age in Ghanaian school girls. Int J Gynecol Obstet [Internet]. 1989 Sep 1 [cited 2018 Sep 30];30(1):63-8. Available from: http://doi.wiley.com/10.1016/0020-7292\%2889\%2990217-8

32. Ameade EPK, Garti HA. Age at menarche and factors that influence it: A study among female university students in Tamale, Northern Ghana. PLoS One. 2016;11(5):1-10.

33. Thakre SB, Thakre SS, Reddy M, Rathi N, Pathak K, Ughade S. Menstrual hygiene: Knowledge and practice among adolescent school girls of Saoner, Nagpur District. J Clin Diagnostic Res. 2011;5(5):1027-33.

34. Article O. Among the Adolescent Girls. 2018;

35. Lawan UM, Yusuf NW, Musa AB. Menstruation and menstrual hygiene amongst adolescent school girls in Kano, Northwestern Nigeria. Afr J Reprod Health. 2010;14(3):201-7.

36. Adhikari P. adolescent girls of Nepal. Knowl Pract regarding menstrual Hyg Rural Adolesc girls Nepal [Internet]. 2007;5(3):382-6. Available from: http://www.wsscc.org/sites/default/files/publications/knowledge-attitude-and-practice-regarding-menstrual-hygiene-in-rural-adolescent-girls-of-nepal2007.pdf

37. Chandra-Mouli V, Patel SV. Mapping the knowledge and understanding of menarche, menstrual hygiene and menstrual health among adolescent girls in low- and middle-income countries. Reprod Health. 2017;14(1):1-16.

38. Thakur H, Aronsson A, Bansode S, Stalsby Lundborg C, Dalvie S, Faxelid E. Knowledge, Practices, and Restrictions Related to Menstruation among Young Women from Low Socioeconomic Community in Mumbai, India. Front Public Heal [Internet]. 2014;2(September 2015). Available from: http://journal.frontiersin.org/article/10.3389/fpubh.2014.00072/abstract

39. Of J. Menstrual Hygiene: Knowledge and Practice among Adolescent School Girls of Saoner, Nagpur District Menstrual Hygiene : Knowledge and Practice among Adolescent School Girls of Saoner, Nagpur District. 2015;(October):1027-33.

40. Raina D, Balodi G. Menstrual Hygiene: Knowledge, Practise and Restrictions Amongst Girls of Dehradun, Uttarakhand, India. Glob J Interdiscip Soc Sci. 2014;3(4):156-62.

41. Garg R, Goyal S, Gupta S. India moves towards menstrual hygiene: Subsidized sanitary napkins for rural adolescent girls - Issues and challenges. Matern Child Health J. 2012;16(4):767-74.

42. Gultie T, Hailu D, Workineh Y. Age of menarche and knowledge about menstrual hygiene management among adolescent school girls in amhara province, Ethiopia: Implication to health care workers \& school teachers. PLoS One. 2014;9(9):1-9.

43. Sommer M, Sahin M. Advancing the global agenda for menstrual hygiene management for schoolgirls. Am J Public Health. 2013;103(9):1556-9.

44. Mahon T, Fernandes M. Menstrual hygiene in South Asia: a neglected issue for WASH (water, sanitation and hygiene) programmes. Gend Dev [Internet]. 2010 Mar 25 [cited 2018 Sep 14];18(1):99-113. Available from: https://www.tandfonline.com/doi/full/10.1080/13552071003600083

45. Of J. Menstrual Hygiene: Knowledge and Practice among Adolescent School Girls of Saoner, Nagpur District Menstrual Hygiene : Knowledge and Practice among Adolescent School Girls of Saoner, Nagpur District. Sci Res Essays [Internet]. 2015 Apr [cited 2018 Sep 5];2(1):1027-33. Available from: http://www.ccsenet.org/journal/index.php/gjhs/article/view/5437

Page $13 / 15$ 
46. Kuhlmann AS, Henry K, Wall LL. Menstrual Hygiene Management in Resource-Poor Countries. Obstet Gynecol Surv. 2017;72(6):356-76.

47. Girls SA, Challenges T. Save the Children: Puberty Education and Menstrual Hygiene Management Supporting Adolescent Girls. 2016 ;(March):1-4. Available from: http://www.savethechildren.org/atf/cf/\%7B9def2ebe-10ae-432c-9bd0-df91d2eba74a\%7D/PUBERTY EDUCATION AND MENSTRUAL HYGIENE MANAGEMENT FACT SHEET 2016 3-20-16.PDF

48. Jain R, Anand P, Dhyani A, Bansal D. Knowledge and awareness regarding menstruation and HIV/AIDS among schoolgoing adolescent girls. J Fam Med Prim care [Internet]. 2017 [cited 2018 Sep 13];6(1):47-51. Available from: http://www.ncbi.nlm.nih.gov/pubmed/29026748

49. Haque SE, Rahman M, Itsuko K, Mutahara M, Sakisaka K. The effect of a school-based educational intervention on menstrual health: An intervention study among adolescent girls in Bangladesh. BMJ Open. 2014;4(7):1-9.

50. Sapkota D, Sharma D, Pokharel HP, Budhathoki SS, Khanal VK. Knowledge and practices regarding menstruation among school going adolescents of rural Nepal. J Kathmandu Med Coll [Internet]. 2014;2(3):122-8. Available from: http://nepjol.info/index.php/JKMC/article/view/9962

51. A Sadiq M. Knowledge and Practice of Adolescent Females about Menstruation in Baghdad. J Gen Pract [Internet]. 2013;02(01):10-3. Available from: http://www.esciencecentral.org/journals/knowledge-and-practice-of-adolescent-females-about-menstruation-in-baghdad.pdf-2329-9126.1000138.php? aid $=22015$

52. Alam MU, Luby SP, Halder AK, Islam K, Opel A, Shoab AK, et al. Menstrual hygiene management among Bangladeshi adolescent schoolgirls and risk factors affecting school absence: Results from a cross-sectional survey. BMJ Open. 2017;7(7):1-10.

53. Sommer M, Caruso BA, Sahin M, Calderon T, Cavill S, Mahon T, et al. A Time for Global Action: Addressing Girls' Menstrual Hygiene Management Needs in Schools. PLOS Med [Internet]. 2016 Feb 23 [cited 2018 Sep 10];13(2):e1001962. Available from: http://dx.plos.org/10.1371/journal.pmed.1001962

54. Article CMERACC review article. 2012;67(9):554-565.. Cme review article. 2012;67(9):554-65.

\section{Figures}

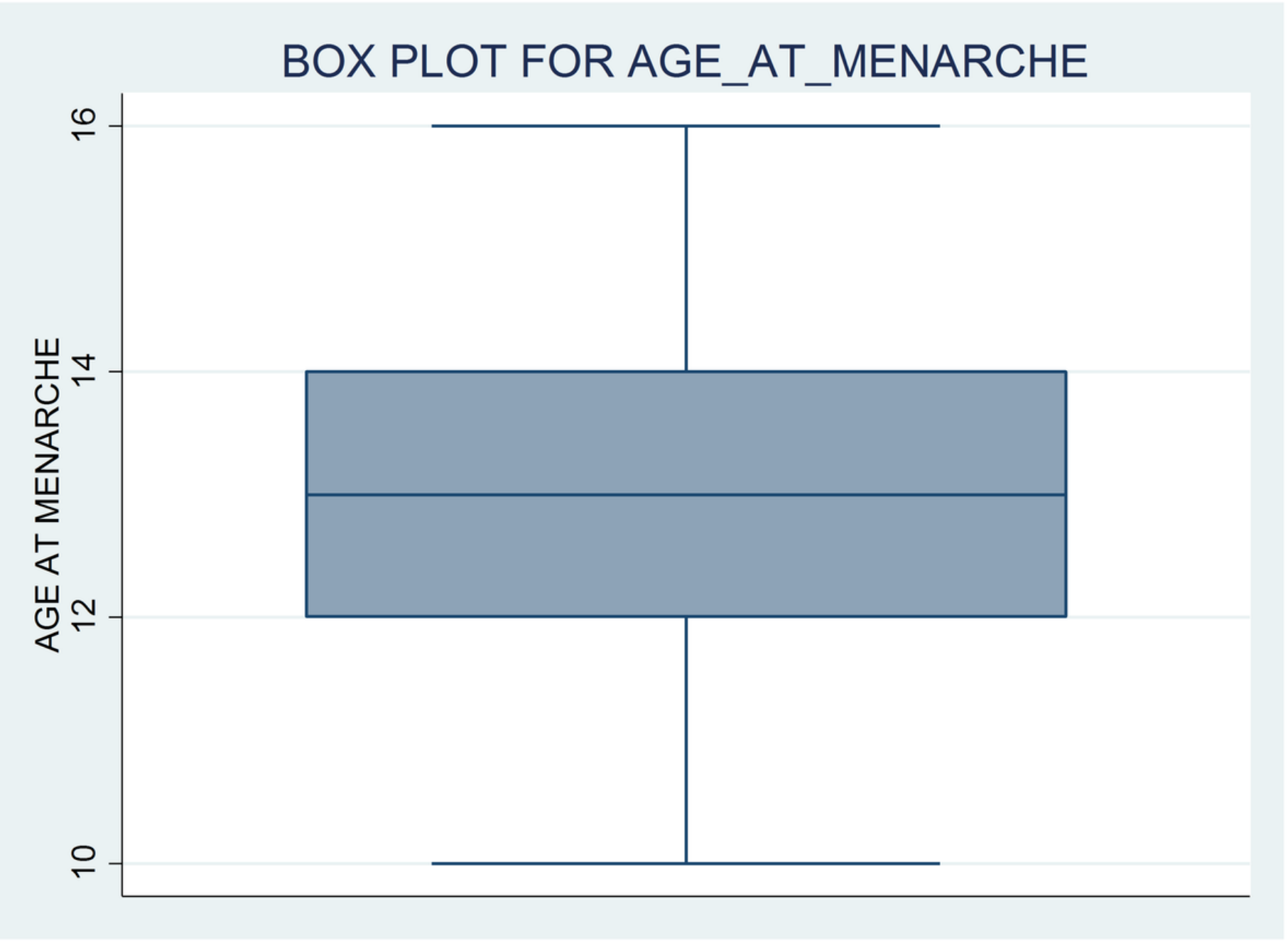

\section{Figure 1}

Box Plot for age at menarche 


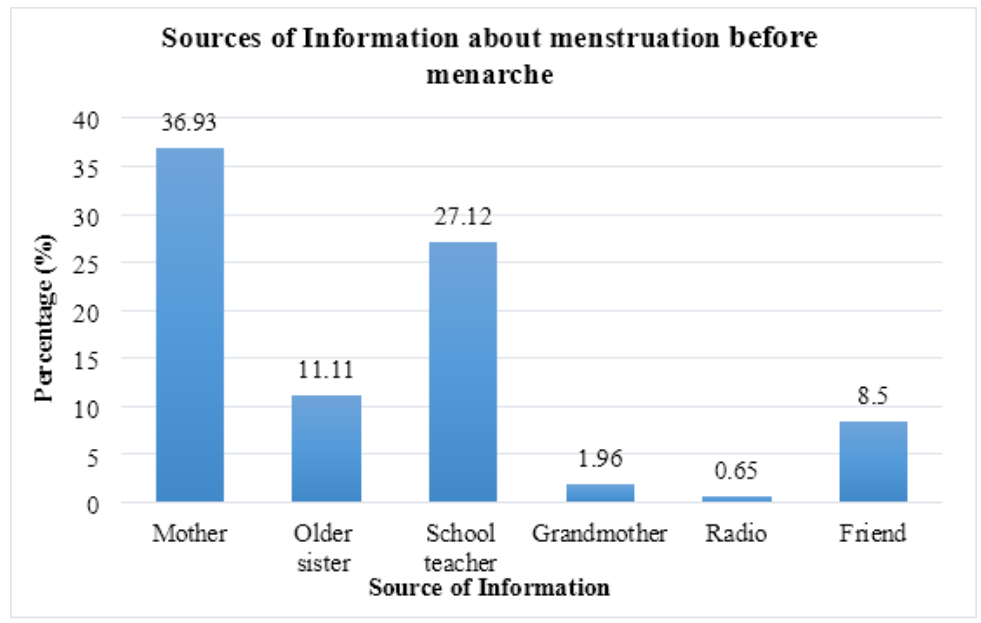

Figure 2

Source of information about menstruation before menarche

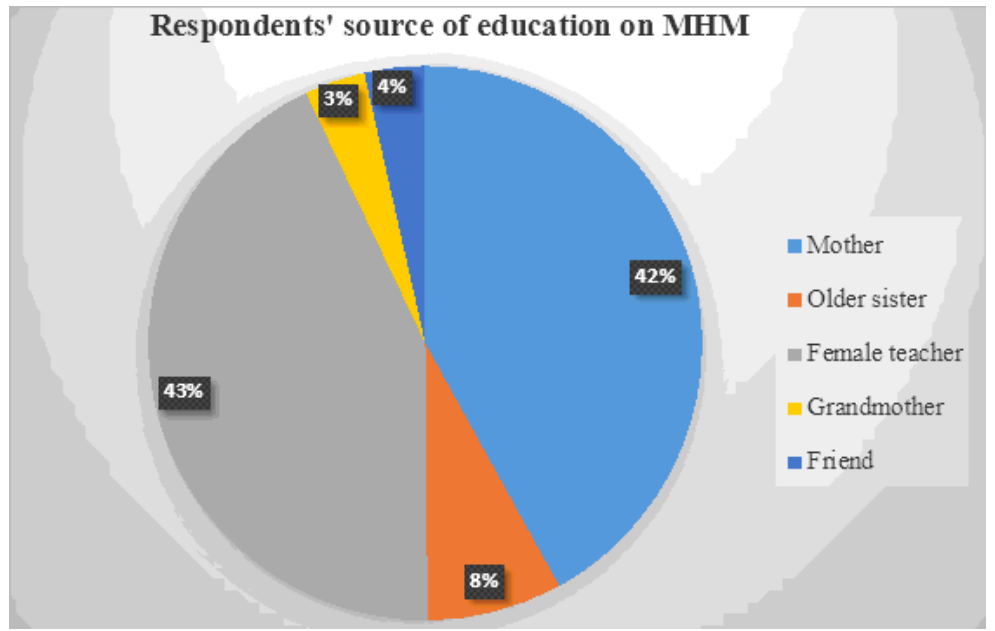

Figure 3

Respondents sources of Education on Menstrual Hygiene Management

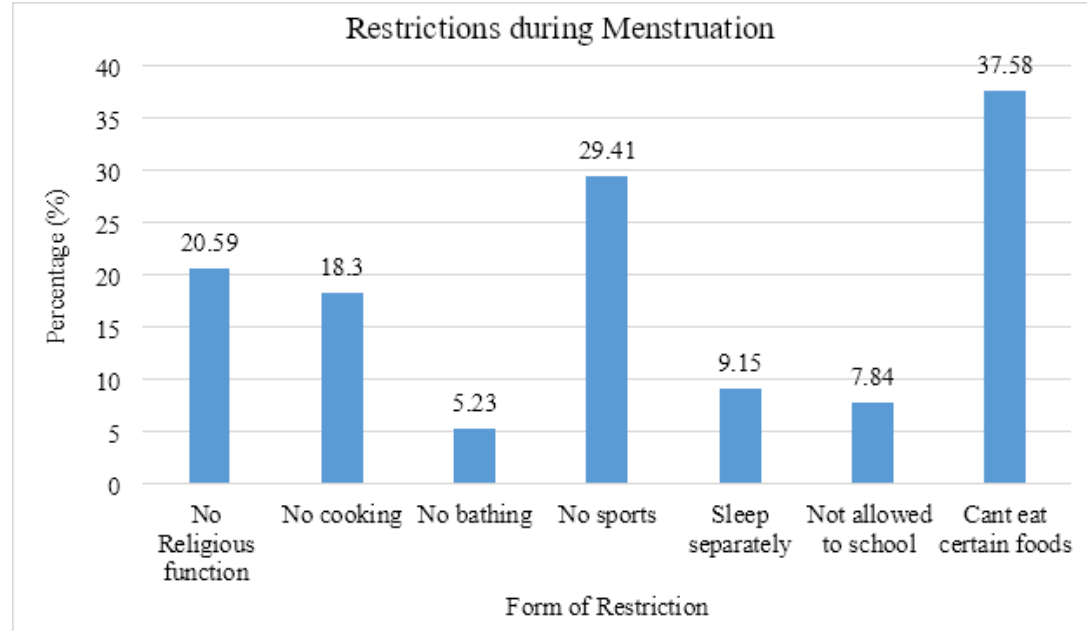

Figure 4

Respondents restrictions during menstruation 